\title{
Legislação brasileira referente à rotulagem nutricional de alimentos ${ }^{1}$
}

\author{
Brazilian food labeling regulations
}

Andréa Benedita FERREIRA2

Ursula Maria LANFER-MARQUEZ2

\section{RE S U M O}

O objetivo deste trabalho é apresentar uma reflexão sobre a evolução histórica da legislação brasileira de alimentos sob o aspecto da rotulagem nutricional, contextualizando as principais leis das últimas quatro décadas, destacando os avanços e identificando os pontos críticos que ainda necessitam de aprimoramento. De uma forma geral pode-se afirmar que, ao longo dos últimos 40 anos, o Brasil aperfeiçoou a sua legislação, incorporando evidências científicas nos regulamentos buscando melhorar a qualidade dos alimentos e promover a Saúde Pública, levando em consideração a realidade brasileira. Contudo, com a publicação da Resolução no 360 da Diretoria Colegiada da Agência Nacional de Vigilância Sanitária em 2003, que retira a obrigatoriedade da declaração dos conteúdos de ferro, cálcio e colesterol dos rótulos, pode-se afirmar que ocorreu uma involução em relação à saúde pública, embora a Resolução tenha mérito em relação à harmonização da legislação com os países membros do Mercosul, permitindo o livre comércio entre estes. Esforços devem ser envidados para que as empresas mantenham a declaração dos nutrientes que deixaram de ser obrigatórios. Ademais, é importante atualizar regulamentos já ultrapassados, incorporar conhecimento novo, preencher lacunas e recomendar ações integradas e contínuas de educação alimentar subsidiadas por pesquisas científicas. A rotulagem nutricional de alimentos é um apoio valioso para os consumidores, dando-lhes a oportunidade de conhecer a composição do alimento, a segurança quanto à ingestão de nutrientes e energia, bem como informações importantes para a manutenção de sua saúde. A legislação na área de alimentos deve ser vista como estratégia para auxiliar na redução dos índices de obesidade, das deficiências nutricionais e das doenças crônicas não-transmissíveis associadas ao padrão de consumo.

Termos de indexação: alimentos; legislação sobre alimentos; rotulagem nutricional.

\section{A B S T R A C T}

The objective of this work is to present a reflection on the historical evolution of the Brazilian food legislation and to emphasize nutritional labeling. The main regulations which have been under way for the four past

\footnotetext{
${ }^{1}$ Artigo elaborado a partir da dissertação de A.B. FERREIRA, intitulada "Conhecendo melhor a rotulagem nutricional dos alimentos: uma análise crítica". Faculdade de Ciências Farmacêuticas, Universidade de São Paulo; 2004.

2 Universidade de São Paulo, Faculdade de Ciências Farmacêuticas, Departamento de Alimentos e Nutrição Experimental. Av. Prof. Lineu Prestes, 580, Cidade Universitária, 05508-900, São Paulo, SP, Brasil. Correspondência para/Correspondence to: A.B. FERREIRA. E-mail: <abfzan@yahoo.com.br>.
} 
decades were highlighted as well as some topics in the regulations which should be improved. From a general point of view, during this period, advances in the legislation have been observed, considering that scientific reports were incorporated in the regulations intending to improve food quality and to promote public health on account of the specific demands of the Brazilian reality. Nevertheless, according to the Regulation nr.360 of the Collegiate Directorate of the Agência Nacional de Vigilância Sanitária in 2003, which states that the declaration of iron, calcium and cholesterol contents is not obligatory anymore, an involution could be assumed regarding public health. Yet, the regulation has its merit by uniformizing the legislation of the countries which compose the Mercosul, providing free trading. Efforts should be made in order to maintain on food labels the nutrients whose declaration is not obligatory anymore. Moreover, it seems to be important to update the regulations, to fill in gaps and to recommend integrated actions of education in food, based on scientific evidences. Food labels have been an useful tool to consumers by giving them the opportunity to know about the composition, nutrient and energy contents as well as informations regarding health maintenance. Food legislation should be considered a strategy to help reduce obesity, nutritional deficiencies and even to prevent the most common chronic noncommunicable diseases associated with intake patterns.

Indexing terms: food; legislation food; nutritional labeling.

\section{N T R O D U Ç Ã O}

Anteriormente à publicação das leis brasileiras referentes a alimentos, os problemas de alimentação e nutrição eram discutidos no âmbito de congressos e reuniões de comissões governamentais, resultando, na maioria das vezes, apenas na publicação de material didático e informativo.

A Comissão Nacional de Alimentação (CNA) foi criada em 1945, pelo Decreto-Lei no 7328 , com a incumbência de avaliar o estado nutricional e os hábitos alimentares da população brasileira ${ }^{1}$. Entre os diversos relatórios apresentados pela CNA, sobressai-se aquele referente ao "Congresso de Nutrição do Hemisfério Ocidental" ocorrido em 1965, em Chicago, nos EUA. Nesse Congresso, apontou-se a desnutrição energético-protéica (DEP) como sendo o problema mais grave na América Central e na América do Sul, e que afetava seriamente as crianças em idade pré-escolar. Outro aspecto discutido foi o crescimento populacional, que não estava sendo acompanhado pelo aumento da oferta de alimentos. Dessa forma, para aliviar a fome, a desnutrição e as necessidades de proteínas, foi sugerida a introdução de alimentos não-convencionais, como farinhas de sementes oleaginosas tais como soja, algodão, amendoim e outras, além da inclusão de produtos do mar, destacando-se a farinha de peixe. Também foram estimuladas melhorias na agricultura, industrialização, comercialização e no transporte dos alimentos como medidas imprescindíveis para o aumento da produção e da produtividade, bem como da redução de perdas pós-colheita ${ }^{2}$. Outro importante tema discutido nesse congresso foi a necessidade da criação de uma legislação adequada para todas as etapas relacionadas à cadeia agroindustrial produtora de alimentos.

Naquele mesmo ano (1965), indo ao encontro das propostas do Congresso de Nutrição do Hemisfério Ocidental, foi realizado o primeiro Simpósio Brasileiro de Alimentação e Nutrição (SIBAN), que teve como objetivo retratar a situação alimentar e nutricional da população do País e apresentar recomendações para diferentes órgãos do governo: ao Congresso Nacional foi recomendada a necessidade de completar e aprovar um Código Nacional de Alimentação, que deveria garantir o "valor nutritivo e as qualidades sanitárias dos alimentos" ${ }^{3}$, uma vez que a desnutrição protéica, o bócio e a cárie dental haviam sido apontados como os principais problemas nutricionais da população brasileira; ao M inistério da Indústria e Comércio sugeriu-se um subsídio às indústrias para que estas proporcionassem alimentos de baixo custo e reconhecido valor protéico, visando atenuar a desnutrição protéica; ao M inistério da Indústria foi sugerido que apoiasse e incentivasse a instalação de fábricas de fertilizantes, com o objetivo de aumentar o rendimento agrícola. Aconselhou-se à Superintendência do Desenvolvimento da Pesca (SUDENE), a adoção de medidas capazes de viabilizar a ampliação da indústria nacional da pesca. Em relação ao bócio, foi recomendado que o Instituto do Sal fiscalizasse 
e exigisse a iodação de todo o sal consumido no País, em percentuais mais adequados. E, por fim, ao M inistério da Saúde e às Secretarias de Saúde dos Estados e Municípios aconselhou-se, como medida imediata, a fluoretação das águas de abastecimento, como forma de solucionar o problema da cárie dentária ${ }^{3,4}$.

Em 1968, ocorreu o segundo SIBAN e, como nenhuma alteração nos índices de desnutrição protéica da população do Brasil havia sido reportada, foram apresentadas propostas mais incisivas para aumentar a disponibilidade de alimentos, bem como programas de incentivo ao consumo de alimentos ricos em proteínas ${ }^{3}$. Nesse mesmo SIBAN, recomendou-se ao Ministério da Saúde, por intermédio da Comissão Nacional de Normas e Padrões para Alimentos (CNNPA) que elaborasse, em caráter prioritário, um anteprojeto de lei que deveria conter, principalmente, a conceituação bromatológica e o estabelecimento de padrões mínimos de identidade de diversos gêneros alimentícios ${ }^{4}$.

Nos anos subseqüentes, as recomendações sugeridas pelos dois Simpósios Brasileiros de Alimentação e Nutrição foram atendidas ao menos parcialmente por ações das autoridades, em programas lançados pelo governo. Entre estes destacou-se o Programa Nacional de Alimentação e Nutrição (PRONAN II), de 1975, que por intermédio do Instituto Nacional de Alimentação e Nutrição (INAN) elaborou vários projetos para atenuar problemas relativos à nutrição e à disponibilidade de alimentos para a população brasileira ${ }^{5,6}$.

Assim, a necessidade de normatização dos procedimentos para a fabricação de alimentos e o estabelecimento de padrões de identidade e de qualidade constituíram terreno propício para o surgimento das primeiras leis referentes a alimentos.

\section{Evolução histórica da legislação alimentícia}

A publicação das primeiras leis ocorreu no final da década de 60, destacando-se, em 1969, o Decreto-Lei no 986. Este, apesar de apresentar definições e procedimentos que foram posteriormente incorporados em outras publicações, ainda continua vigente, devido à sua abrangência. Essa publicação estabelece definições sobre alimentos, procedimentos para o registro e controle, rotulagem, critérios de fiscalização e detecção de alterações ${ }^{7}$.

Todavia, na publicação citada não é abordada a rotulagem nutricional, uma vez que os conteúdos em nutrientes ainda eram pouco conhecidos. A primeira tabela nacional de composição de alimentos do Estudo Nacional de Despesa Familiar (ENDEF) foi publicada apenas em $1977^{8}$.

Em relação à identidade e à qualidade, 0 Decreto-Lei no 986 de 1969 determina a criação de um padrão de identidade para cada tipo de alimento, sendo obrigatório constar a sua descrição, os procedimentos de higiene e práticas de fabricação, os aditivos permitidos e seus respectivos limites, os procedimentos de amostragem para a sua análise, bem como a rotulagem ${ }^{7}$. Esses padrões de identidade deveriam ser elaborados e publicados o quanto antes pela CNNPA, porém, a maioria foi publicada somente a partir de 1975 , como será relatado mais adiante.

As publicações do período de 1970 a 1973 não foram numerosas nem relevantes. A pesar de ter sido recomendada, já no primeiro SIBAN em 1965, a iodação do sal tornou-se obrigatória apenas em 1974, com a promulgação da Lei no $6.150^{\circ}$. Essa medida visava adequar os teores de iodo no sal para solucionar a elevada incidência de bócio no País e exigir uma fiscalização mais rigorosa pelos órgãos responsáveis. No ano seguinte, em 1975, houve a publicação do Decreto no 75.697, que estabelece os padrões de identidade e qualidade para $0 \mathrm{sal}^{10}$. Os dois regulamentos mencionados ainda vigoram. Porém, o artigo primeiro da Lei no 6.150 de 1974 foi alterado em 1995, com a publicação da Lei no $9.005^{11}$, e passou a vigorar com a seguinte redação: "É proibido, em todo o Território Nacional, expor ou entregar ao consumo direto sal comum ou refinado que não contenha iodo nos teores 
estabelecidos em Portaria do M inistério da Saúde". Esta lei deveria ter revogado a Lei no 6.150 de 1974, unificando os dois regulamentos e apresentando apenas uma versão, porém atualizada.

Em 1977, ocorreu a publicação da Resolução n 33 da CNNPA, ainda vigente, que orienta os fabricantes de alimentos quanto aos princípios gerais de higiene a serem adotados em todas as etapas, desde a obtenção da matéria prima até a distribuição dos alimentos ${ }^{12}$. Essa publicação marcou o início da prática do controle sanitário.

Em atendimento ao Decreto-Lei no 986 de 1969, a CNNPA publicou, no ano de 1978, uma importante série de regulamentos com o objetivo de estabelecer Padrões de Identidade e Qualidade (PIQ). Foram publicados ao todo 47 padrões de identidade e qualidade relativos a alimentos e bebidas, por meio da Resolução no 12 CNNPA $^{13}$. Desses, alguns já foram revogados por publicações mais recentes, enquanto outros permanecem vigentes.

Elaborada em 1978, mas publicada apenas no início de 1979, a Resolução Normativa no 12/78, da Câmara Técnica de Alimentos (CTA), foi a primeira a estabelecer termos que deveriam constar obrigatoriamente no rótulo de alimentos embalados. Enfatizou-se a distribuição e disposição das informações nos diversos tipos de embalagens e o que deveria constar no painel frontal (nome, marca, conteúdo e declaração específica) e nos painéis laterais (relação de ingredientes, aditivos intencionais e nome do País de origem) ${ }^{14}$. Essa resolução foi revogada apenas em 1998, com a publicação da Portaria no 42 da Secretaria de Vigilância Sanitária do Ministério da Saúde (SVS/MS), que não apenas revisou o conteúdo do regulamento anterior, mas também tornou obrigatória a identificação do lote, do prazo de validade e de instruções sobre o preparo e uso dos alimentos, caso necessário.

Nos anos seguintes, entre 1979 e 1991, ocorreram outras publicações que, apesar da sua relevância, não serão mencionadas por não estarem diretamente relacionadas com informações nutricionais. Nesse período, os avanços na área da química analítica e a adoção de novas metodologias e procedimentos de análise, além de estudos epidemiológicos sobre o estado de saúde da população brasileira e a sua estreita correlação com a alimentação, foram alguns dos fatores que contribuíram para a evolução da legislação brasileira e na incessante busca pelo bem estar da população.

Neste contexto, em 1992 foi promulgada a Lei $n$ ㅇ 8.543, ainda em vigência, que determina a obrigatoriedade da declaração da presença de glúten nos rótulos e embalagens dos alimentos que o contém, tais como trigo, aveia, cevada, malte, centeio, triticale e/ou derivados ${ }^{15}$, como medida importante para alertar a população acometida de uma reação auto-imune que afeta o intestino delgado, denominada síndrome celíaca. Já em 1993, ocorreu a publicação da Portaria no 1.428, do Ministério da Saúde, que orienta os fabricantes sobre Boas Práticas de Produção e Prestação de Serviço e também determina como os estabelecimentos devem proceder para a criação e elaboração de Padrões de Identidade e Qualidade para produtos e serviços, e introduziu a "Análise de Perigos e Pontos Críticos de Controle" (APPCC) ${ }^{16}$.

Em 1994, o M inistério da Saúde publicou a Portaria $n$ ㅇ 2.160 criando o "Programa Nacional de Controle da Deficiência de Vitamina A" sugerindo a ingestão de megadoses de vitamina A, suplementação de alimentos com esta vitamina ou pró-vitamina A e promovendo campanhas de educação nutricional, como intervenção para reduzir a incidência de hipovitaminose A no País, principal causa de cegueira evitável. 0 alvo eram crianças de 6 meses a 5 anos de idade, residentes em áreas consideradas de risco ${ }^{17}$.

No ano de 1997, a Portaria no 326 SVS/MS, ainda vigente, foi outra publicação que aborda novamente a questão do controle sanitário ${ }^{18}$. Embora mais detalhada, ela é similar à Resolução no 33 de 1977, pois procura adequar normas brasileiras às do Mercosul. A publicação desta Portaria deveria ter revogado a Resolução no 33 de 1977 por abranger praticamente os mesmos itens, 0 que, contudo, não aconteceu. 
No Brasil, o final da década de 1990 foi marcado por importantes publicações na área de alimentos, como reflexo do que vinha sendo discutido intensamente no cenário internacional.

Merece destaque a publicação de duas portarias: a Portaria no 41 e a no 42 da SVS/MS, de 1998, correspondentes à Rotulagem Nutricional e à Rotulagem Geral de Alimentos Embalados, respectivamente, reconhecendo-se, pela primeira vez, a importância da regulamentação do conteúdo de nutrientes, ainda que a sua declaração fosse facultativa para os alimentos em geral. A Portaria no 41 SVS/M S tornou a rotulagem nutricional obrigatória apenas para aqueles alimentos nos quais se quisesse ressaltar alguma propriedade nutricional (informação nutricional complementar). Neste último caso, a informação nutricional deveria ser expressa por $100 \mathrm{~g}$ ou $100 \mathrm{~mL}$ do alimento e deveriam constar, obrigatoriamente, o valor energético, os conteúdos de proteínas, carboidratos, lipídios e fibra alimentar; sendo opcional a declaração de outros nutrientes, tais como vitaminas $^{19}$. A preocupação com rótulos contendo afirmações enganosas conferindo aos alimentos efeitos benéficos sem confirmação científica, foi objeto da Portaria $n-42$, que estabelecia que os rótulos não devem apresentar dizeres atribuindo aos alimentos propriedades que não possuem. Logo, os rótulos não deveriam dar destaque à presença ou ausência de componentes que não fossem próprios do alimento, nem indicar propriedades medicinais ou terapêuticas, ou sugerir o consumo para melhorar a saúde ou evitar doenças, entre outras orientações ${ }^{20}$.

Ainda no ano de 1998, foi publicada a Portaria no 27 SVS/MS, ainda vigente, que complementa a Portaria $\mathrm{n} 041$, regulamentando a apresentação da informação nutricional complementar. Esta é definida como "qualquer representação que afirme, sugira ou implique que um alimento possui uma ou mais propriedades nutricionais particulares, relativas ao seu valor energético e ao seu conteúdo de proteínas, gorduras, carboidratos, fibras alimentares, vitaminas e minerais". Assim, são estabelecidos os critérios para que atributos nutricionais específicos, tais como "baixo conteúdo", "fonte", "alto teor", "reduzido", "aumentado", etc., possam ser destacados. Já os termos "reduzido" e "aumentado" devem ser utilizados para destacar, em termos comparativos, as propriedades de um produto novo, em relação a um produto convencional21.

No mesmo ano ainda foram definidos e regulamentados, pela primeira vez, por meio da publicação da Portaria no 29 SVS/M S, os alimentos destinados a pessoas em condições metabólicas ou fisiológicas especiais, denominados de "Alimentos para Fins Especiais", classificando-os em três categorias: "Alimentos para Dietas com Restrição de Nutrientes", "Alimentos para Ingestão Controlada de Nutrientes" e "Alimentos para Grupos Populacionais com Necessidades Específicas" ${ }^{22}$. Deve-se ressaltar também, em 1998, a Portaria no 31 SVS/MS, que revogou o item "Alimentos Enriquecidos" da Resolução № 12 CNNPA, de 1978, e aprovou o "Regulamento Técnico referente a Alimentos Adicionados de Nutrientes Essenciais" Nesse regulamento os alimentos são diferenciados em duas classes: "Alimentos Enriquecidos ou Fortificados" e "Alimentos Restaurados", ou "com Reposição $\mathrm{de}^{23}$. Essas duas Portarias mencionadas, ainda em vigor, determinam que a rotulagem para esses tipos de alimentos deve seguir as normas de rotulagem geral, nutricional, além de regulamentos específicos, como a Portaria no 27 SVS/M S sobre Informação Nutricional Complementar (caso houver alegação de propriedade nutricional). Naquele ano, foram estabelecidos, pela primeira vez, os valores de "Ingestão Diária Recomendada" (IDR) pela Portaria $\mathrm{n}$ o 33 SVS/M S ${ }^{24}$, revogada em setembro de 2005 pela Resolução da Diretoria Colegiada - RDC no 26925. A pesar da atualização das IDR com a publicação da RDC nㅇ 269, os valores de proteína e ácido fólico para adultos diferem dos apresentados em outro regulamento também vigente, a RDC no 360/2003, evidenciando uma contradição. Essa falha deveria ser corrigida para evitar dúvidas e erros na elaboração dos rótulos. 
É notável que o ano de 1998 contribuiu com importantes publicações voltadas, não somente para a rotulagem de alimentos, mas também com regulamentos que estabelecem critérios para a elaboração de alimentos diferenciados.

Em continuidade ao breve histórico acerca da implementação da legislação brasileira foi publicada em 1999 a Lei no 9.782, que define 0 Sistema Nacional de Vigilância Sanitária (SNVS) e cria a Agência Nacional de Vigilância Sanitária (ANVISA), vinculada ao M inistério da Saúde ${ }^{26}$. No mesmo ano, o Decreto no 3.029 regulamentou a ANVISA, que passou a ser de responsabilidade de uma Diretoria Colegiada27. Já a Resolução no 58 ANVS/MS, de 1999, determina que a regulamentação de todos os seus produtos e serviços seja divulgada por meio de Resoluções RDC (Resolução da Diretoria Colegiada) ${ }^{28}$.

Ainda em 1999, foi publicada pelo Ministério da Saúde, a Portaria $\mathrm{n}$ - 710, que institui a "Política Nacional de Alimentação e Nutrição" (PNAN) e apontou os órgãos que devem aplicar a política da qualidade, elaborar ou readequar seus planos, programas, projetos e atividades, de acordo com diretrizes previamente estabelecidas. Essa portaria destaca novamente que uma das prioridades deve ser a prevenção da deficiência de micro-nutrientes, uma vez que estudos epidemiológicos continuavam evidenciando um quadro preocupante em relação à vitamina $A$, ao ferro $e$ ao iodo ${ }^{29}$. Todas as regulamentações de 1999 permanecem vigentes.

Devido à anemia ferropriva representar uma importante questão de saúde pública no Brasil e ocorrer, principalmente, em mulheres no período fértil e em crianças menores de dois anos, e considerando-se a prevalência da deficiência de ferro em, aproximadamente, $50 \%$ das crianças em idade pré-escolar, em $20 \%$ dos adolescentes e em $15 \%$ a $30 \%$ das gestantes de regiões diferentes do País, foi publicada, em 2000, a RDC no 15. Essa Resolução obriga a fortificação de farinhas de trigo e de milho com ferro ${ }^{30}$. Em 2002, essa RDC foi substituída pela RDC $n=344$, que torna obrigatória a fortificação dessas farinhas, não apenas com ferro, mas também com ácido fólico, indo ao encontro das recomendações da Organização Mundial da Saúde (OMS) e da Organização Panamericana de Saúde (OPAS) ${ }^{31}$. A legislação brasileira apresentou um importante avanço em 2000, com a RDC no 94, que tomou de surpresa 0 setor produtivo que estava se adequando ainda às exigências da Portaria $n-41$ de 1998. A rotulagem nutricional, que era obrigatória apenas para alimentos que destacavam alguma propriedade nutricional ou alimentos com propriedades específicas, passou a ser obrigatória para todos os alimentos e bebidas embalados, por meio da RDC no 94, que revogou a Portaria no 41.

A RDC no 94 de 2000 manteve a obrigatoriedade dos mesmos itens regulamentados anteriormente (valor energético, proteínas, gorduras, carboidratos e fibra alimentar) e acrescentou gorduras saturadas, colesterol, cálcio, ferro e sódio. A informação obrigatória deveria ser expressa, por $100 \mathrm{~g}$ ou $100 \mathrm{~mL}$ de alimento e por porção e o rótulo deveria indicar o número de porções contidas na embalagem ${ }^{32}$. No entanto, até a data da publicação desse regulamento as porções ainda não haviam sido definidas. Isso ocorreu em 2001, com a divulgação da $R D C n=39$, regulamento que estabeleceu a porção de referência para os diferentes grupos de alimentos, com base na pirâmide alimentar, um instrumento, sob forma gráfica, com a finalidade de orientar a população, visando uma alimentação mais saudáve| ${ }^{33,34}$.

A vigência da $R D C$ no 94 de 2000 foi curta, sendo substituída no início de 2001 pela RDC no 40, que instituía a obrigatoriedade da declaração dos nutrientes por porção e sua porcentagem em relação à IDR, ou seja, a inclusão da \% valor viário (VD), tomando como base uma dieta de $2500 \mathrm{kca}^{35}$. Os itens que deveriam ser declarados, obrigatoriamente, continuaram a ser os mesmos que constavam na RDC no 94.

Em 2002, a Portaria no 42 de 1998, referente à Rotulagem Geral de Alimentos e Bebidas Embalados, foi revogada e substituída pela RDC no 259, similar à publicação anterior, tendo sido 
excluídas definições desnecessárias, e outras, atualizadas. Com essa publicação, os rótulos devem apresentar, obrigatoriamente, a denominação de venda do alimento (marca), a lista de ingredientes, o conteúdo líquido, a identificação de origem, o prazo de validade, a identificação do lote, na forma de código, data de fabricação ou de validade e as instruções sobre o preparo do alimento, quando necesssário ${ }^{36}$. Também em 2002, devido à falta de uniformidade na rotulagem dos alimentos contendo glúten, houve a publicação da RDC $\mathrm{n} 040$, responsável pela padronização da declaração nos rótulos de alimentos e bebidas, com a advertência: "CONTÉM GLÚTEN" ${ }^{37}$. Ainda referente a esse assunto, em 2003, foi publicada a Lei $n$ - 10.674, que determina que todos os alimentos devem apresentar em seus rótulos a inscrição: " contém Glúten" ou " não contém Glúten" 38 . Por conseqüência, atualmente há três regulamentos sobre glúten em vigor: a Lei no 8.543 de 1992 que exige do fabricante a declaração da presença de glúten nos alimentos que o contém; a RDC $n \circ 040$ de 2002, que estabelece como deve ser mencionada a presença de glúten nos rótulos e a Lei $n-10.674 / 2003$, que obriga que todos os alimentos apresentem a inscrição, "contém" ou "não contém", como medida de orientação aos consumidores com doença celíaca. Na vigência da Lei $n=10.674$, a Lei $n=8.543$ deveria ser revogada, pois são regulamentos contraditórios.

A RDC no 275, publicada em 2002, visava complementar publicações anteriores e aperfeiçoar o controle sanitário dos alimentos, por meio do "Regulamento Técnico de Procedimentos Operacionais Padronizados" e a "Lista de Verificação das Boas Práticas de Fabricação em Estabelecimentos Produtores/Industrializadores de Alimentos" ${ }^{39}$. Assim, em relação à higiene e às boas práticas de fabricação dos alimentos, apesar dos intervalos de tempo entre as publicações, observase melhoria contínua.

Referente à comercialização de sal, além das publicações de 1974 e 1975, houve publicações posteriores, com revisão dos teores mínimos e máximos de iodo a serem adicionadas ao sal, como a Portaria no 218 de $1999^{40}$ e a RDC no 32 de $2003^{41}$, já revogadas. 0 regulamento atual sobre iodação do sal é a RDC № 130 de $2003^{42}$.

Visando estabelecer uma equiparação da legislação brasileira com a dos países da América Latina que compõem o Mercosul foram publicadas, em dezembro de 2003, as Resoluções da Diretoria Colegiada no 359 e no 360 e estabeleceu-se o prazo de até 31 de julho de 2006 para os fabricantes de alimentos adequarem os seus rótulos às Resoluções. É importante mencionar que as empresas, que haviam acabado de alterar os rótulos conforme às exigências das RDC $\mathrm{n} 039 \mathrm{e}$ no 40 , foram novamente surpreendidas com a revogação dessas Resoluções.

A RDC $n$ 360, que causou o maior impacto tanto no setor produtivo como consumidor, estabelece que a rotulagem nutricional compreende a declaração obrigatória do valor energético e de nutrientes (carboidratos, proteínas, gorduras totais, saturadas, gorduras trans, fibra alimentar e sódio), bem como a informação nutricional complementar relativa à declaração facultativa de propriedades nutricionais. Ademais, vitaminas e sais minerais podem ser declarados opcionalmente, desde que cada porção do alimento contenha pelo menos $5 \%$ da IDR ${ }^{43}$. Assim, qualquer declaração de propriedade nutricional deve vir acompanhada da apresentação de conteúdo do nutriente ao qual se refere o destaque nutricional. Essa RDC, apesar de se referir especificamente à rotulagem nutricional, não é o único dispositivo legal sobre esse assunto, de modo que outros regulamentos foram incluídos nesta revisão.

Cumpre destacar que a declaração de ferro, cálcio e colesterol, por sua vez, tornou-se facultativa desde dezembro de 2003, enquanto a declaração de gorduras trans passou a ser obrigatória, seguindo uma tendência internacional. Todavia, é importante ressaltar que os teores de ferro, cálcio e colesterol, que já constam nos rótulos de muitos alimentos, são informações úteis tanto para os consumidores quanto para os profissionais da área de saúde que podem deixar de existir. Embora parte da população brasileira 
ainda não tenha adquirido o hábito de ler o rótulo de alimentos, outra parte, aquela preocupada com o bem estar e a saúde, proporcionados por uma alimentação adequada, já está acostumada a encontrar informações sobre o conteúdo e o valor diário de ferro, cálcio e colesterol. Esses dados, referentes aos teores desses nutrientes e que compõem o banco de dados analíticos de muitos fabricantes, por não mais serem obrigatórios, serão perdidos, com evidente prejuízo para a população, representando um verdadeiro retrocesso na evolução da legislação.

Quanto à declaração de gorduras trans nos rótulos, embora siga modelos do exterior, foi implementada sem que fosse acompanhada de campanhas de esclarecimento da população, que se ressente da falta do conhecimento do que venha a ser gordura trans, podendo ser interpretado esse termo até como "transgênico". Outra informação obrigatória, embora pouco conhecida pelos consumidores, é a declaração do valor energético não apenas em kcal como também em kJ, unidade não usual no Brasil.

Na RDC no 360, certos alimentos, como vinagres, sal, café, erva mate, chás, produtos a granel, frutas, vegetais, carnes in natura, entre outros, foram isentados da declaração de informação nutricional. No caso dos gêneros alimentícios a granel, a RDC no 40 recomendava a divulgação da declaração nutricional na forma de cartazes, folhetos, etiquetas, etc. Essa recomendação deveria ter sido mantida na RDC no 360, porque independente da forma de apresentação do produto, o consumidor tem o direito de ter acesso à informação nutricional ao adquiri-lo. Além disso, a comercialização de produtos a granel merece incentivo, pois gera menor quantidade de lixo. Essa falha foi corrigida no M anual de Orientação às Indústrias de Alimentos, publicado pela ANVISA em $2005^{44}$

Vale salientar que na RDC no 360 as regras de arredondamento foram notadamente simplificadas tendo sido adotados critérios mais simples e de maior clareza em relação à RDC no 40 o que representa um aspecto positivo. A variação permitida nos valores declarados nos rótulos dos alimentos permite uma tolerância para mais ou para menos de $20 \%{ }^{43}$.

Já a RDC no 359 se diferencia da legislação anterior (RDC no 39, 2001), principalmente por reduzir a base da alimentação diária brasileira de 2500 para $2000 \mathrm{kcal}$. Em função disso, foram redefinidos o valor energético e o número de porções dos alimentos, classificados em quatro níveis e oito grupos, apesar de a atual RDC não mencionar 0 modelo de pirâmide alimentar adotado $^{45}$. Esse regulamento reúne no Grupo VIII: "Molhos, temperos pratos, caldos, sopas e pratos preparados", entretanto, como no grupo IX, correspondente aos mesmos alimentos, na RDC no 39 de 2002, nenhuma informação sobre valor energético médio do grupo e número de porção recomendada é fornecida. Tendo em vista o fato de sopas e pratos prontos terem-se tornado cada vez mais presentes na alimentação da população das grandes cidades do Brasil, torna-se imprescindível para os consumidores, a padronização do valor energético, também para esse tipo de alimento.

Ainda na RDC no 359, a porção é definida como a quantidade média de cada tipo de alimento que deveria ser consumida em cada ocasião de consumo por pessoas sadias e maiores de 3 anos, para obter uma dieta saudável. Além de redefinir a porção de diversos alimentos, a RDC no 359 institui a obrigatoriedade da medida caseira para expressar a porção de referência. É permitida, nesse caso, uma variação de mais ou menos $30 \%$ no tamanho da porção em relação à porção apresentada no regulamento para produtos apresentados em unidades de consumo ou fracionados, e maior do que $30 \%$ para os alimentos comercializados em embalagem individual ${ }^{42}$. Entretanto, a RDC no 359 não exemplifica quais os produtos que se enquadram em cada grupo, dificultando 0 atendimento à legislação.

A RDC no 359 é mais sucinta que a antiga RDC no 39 que pode, dependendo da situação, resultar em perda de informação. Por exemplo, a $\mathrm{RDC} n-39$ estabelecia que as unidades embaladas 
para consumo individual, contidas em embalagens maiores, apresentassem a informação nutricional, não apenas na embalagem maior, como também em cada unidade interna. Essa orientação era importante, pois garantia que essas embalagens individuais não circulassem sem a rotulagem nutricional. Porém, na atual RDC no 359, nada foi mencionado e conclui-se que fica a critério do fabricante apresentar ou não rotulagem nutricional nesses casos.

\section{O N SIDERAÇÕ ES FIN A IS E PERSPECTIVAS}

Os problemas de saúde da população brasileira vêm de longa data e deram origem, inicialmente, a programas, medidas e intervenções governamentais para a melhoria da segurança e qualidade dos alimentos e, posteriormente, à legislação sobre a rotulagem nutricional de alimentos e bebidas. Esta revisão destacou os regulamentos mais relevantes que resultaram em significativos avanços e pontos da legislação que necessitam de aprimoramento para sanar equívocos e preencher lacunas. Contudo, a legislação sobre rotulagem de alimentos é dinâmica e pode incorpo rar rapidamente novos conhecimentos na área da alimentação e nutrição humana. Assim, 0 aumento da obesidade que se verifica na população em geral, a incidência de alergias alimentares, a necessidade de redefinição das IDR, principalmente para os micronutrientes, a valorização de grãos integrais na alimentação, o papel dos ácidos graxos trans no metabolismo lipídico e a importância da associação entre o consumo de alimentos e a atividade física, são apenas alguns dos tópicos que deverão orientar futuras pesquisas e ações governamentais em rotulagem, voltadas para uma alimentação saudável.

Em relação à retirada da obrigatoriedade da declaração de cálcio, ferro e colesterol nos rótulos, sugere-se incentivar as indústrias a manterem a declaração desses nutrientes uma vez que essas informações são úteis aos profissionais de saúde e população em geral.
Ademais, seria aconselhável esclarecer à população a respeito da importância da informação nutricional e de como utilizá-la em benefício da saúde. Isso poderia ser feito na forma de campanhas informativas divulgadas na mídia, nas escolas e junto à classe de profissionais da área de saúde.

\section{REFER Ê N C IAS}

1. Brasil. Ministério da Saúde. Noticiário. Anais da Comissão Nacional de Alimentação. 1967; 1(1):7-10.

2. Monteiro A.M. Congresso de nutrição do hemisfério ocidental. Anais da Comissão Nacional de Alimentação. 1967; 2(1):189-201.

3. Dutra de Oliveira JE. O SIBAN e a problemática brasileira de alimentação e nutrição. Alimentação. 1981; 53:6-11.

4. Associação Brasileira das Indústrias da Alimentação. Conclusões e recomendações dos SIBANs. Alimentação. 1981; 53:22-40.

5. Kohlmann RF. A indústria de alimentos e o SIBAN: algumas reflexões referentes aos resultados. Alimentação, 1981; 53:42-43.

6. Valente JC. O SIBAN e as políticas e programas governamentais na área da alimentação e nutrição. Alimentação. 1981; 53:44-51.

7. Brasil. Decreto-Lei n.986, de 21 de outubro de 1969. Dispõe sobre normas básicas sobre alimentos dos M inistérios da M arinha de Guerra, do Exército e da Aeronáutica Militar. Diário Oficial da União. 196921 out; Seção 1.

8. Instituto Brasileiro de Geografia e Estatística. Estudo Nacional da Despesa Familiar (ENDEF): tabelas de composição de alimentos. Rio de Janeiro; 1985. p. 212 .

9. Brasil. Ministério da Saúde. Visalegis: Legislação em Vigilância Sanitária. Lei n.6.150, de 03 de dezembro de 1974. lodação do sal [acesso em 30 ago 2003]. Disponível em: http://e-legis.bvs.br/ leisref/public/showAct.php?id=29

10. Brasil. Ministério da Saúde. Visalegis: Legislação em Vigilância Sanitária. Decreto n.75.697, de 06 de maio de 1975. Padrões de identidade e qualidade do sal [acesso em 30 ago 2003]. Disponível em: http://e-legis.bvs.br/leisref/public/ showAct.php?id=26

11. Brasil. Ministério da Saúde. Visalegis: Legislação em Vigilância Sanitária. Lei 9.005, de 16 de março de 1995. Altera disposições sobre iodação e controle do sal [acesso em 30 ago 2003]. Disponível em: http://e-legis.bvs.br/leisref/public/ showAct.php? id =270 
12. Brasil. Ministério da Saúde. Visalegis: Legislação em Vigilância Sanitária. Resolução no 33, de 09 de novembro de 1977. Normas gerais de higiene. [acesso em 16 set 2003]. Disponível em: http://elegis.bvs.br/leisref/public/showAct. php?id=6321

13. Brasil. Resolução n.12 - CNNPA, de 24 julho de 1978. A CNNPA do Ministério da Saúde aprova 47 padrões de identidade e qualidade relativos a alimentos e bebidas para serem seguidos em todo território brasileiro. Diário Oficial da União. 1978 24 jul; Seção 1.

14. Brasil. Resolução Normativa n.12/78, de 12 de janeiro de 1979. Câmara Técnica de Alimentos do Conselho Nacional de Saúde. Rotulagem. Diário Oficial da União. 19792 jan; Parte I, 2 jan; Seção 1.

15. Brasil. Ministério da Saúde. Visalegis: Legislação em Vigilância Sanitária. Lei n.8.543, de 23 de dezembro de 1992. Presença de glúten [acesso em 30 ago 2003]. Disponível em: http://e-legis.bvs. br/leisref/public/showAct.php?id=32

16. Brasil. Portaria n.1.428, de 26 de novembro de 1993. O Ministério da Saúde aprova Regulamento Técnico para Inspeção Sanitária de Alimentos, Diretrizes para o Estabelecimento Boas Práticas de Produção e de Prestação de Serviço na Área de Alimentos e o Regulamento Técnico para o Estabelecimento de Padrões de Identidade e Qualidade para Serviços e Produtos na Área de Alimentos. Diário Oficial da União. 19932 dez; (229):18415; Seção 1.

17. Brasil. Portaria n.2.160, de 29 de dezembro de 1994. O Ministério da Saúde divulga o Programa Nacional de Controle das Deficiências de Vitamina A. Diário Oficial da União. 199430 dez; (248): 21262; Seção 1.

18. Brasil. Portaria n.326 SVS/MS, de 30 de julho de 1997. A Secretária de Vigilância Sanitária do MS aprova o regulamento técnico sobre as condições higiênico-sanitárias e de boas práticas de fabricação para estabelecimentos produtores/industrializados de alimentos. Diário Oficial da União. 1997 1 ago; (146):16560; Seção 1.

19. Brasil. Portaria n.41, de 14 de janeiro de 1998. A Secretaria da Vigilância Sanitária do MS aprova o regulamento técnico para rotulagem nutricional de alimentos embalados. Diário Oficial da União. 199821 jan; (14-E):4. Seção 1.

20. Brasil. Portaria n.42, de 14 de Janeiro de 1998. A Secretaria de Vigilância Sanitária do MS aprova o regulamento técnico para rotulagem de alimentos embalados. Diário Oficial da União. 199821 jan; (14):12; Seção 3.

21. Brasil. Portaria n.27 SVS/MS, de 13 de janeiro de 1998. A Secretária de Vigilância Sanitária do MS aprova o Regulamento Técnico referente à Infor- mação Nutricional complementar. Diário Oficial da União. 199816 jan; (11-E):1; Seção 1.

22. Brasil. Portaria n.29 SVS/MS, de 13 de janeiro de 1998. A Secretária de Vigilância Sanitária do MS aprova o Regulamento Técnico referente a Alimentos para Fins Especiais. Diário Oficial da União. 199815 jan; (10-E):8; Seção 1.

23. Brasil. Portaria n.31 SVS/MS, de 13 de janeiro de 1998. A Secretária de Vigilância Sanitária do MS aprova o Regulamento Técnico referente a Alimentos Adicionados de Nutrientes Essenciais. Diário Oficial da União. 199816 jan; (11-E):5; Seção 1.

24. Brasil. Portaria n.33 SVS/MS, de 13 de janeiro de 1998. A Secretária de Vigilância Sanitária do MS adota a Ingestão Diária Recomendada (IDR) para vitaminas, minerais e proteínas. Diário Oficial da União. 199816 jan; (11-E):5; Seção 1.

25. Brasil. Ministério da Saúde. Visalegis: Legislação em Vigilância Sanitária. Resolução da Diretoria Colegiada - RDC n. 269, de 22 de setembro de 2005. Regulamento Técnico sobre a Ingestão Diária Recomendada (IDR) de Proteína, Vitaminas e Minerais [acesso em 30 jan 2006]. Disponível em: http://e-legis.anvisa.gov.br/leisref/public/show Act. php? $\mathrm{id}=18828 \&$ w ord $=$

26. Brasil. Lei n.9.782, de 26 de janeiro de 1999. 0 Congresso Nacional através do MS define o Sistema Nacional de Vigilância Sanitária e cria a Agência Nacional de Vigilância Sanitária. Diário Oficial da União. 199927 jan; (18):1; Seção 1.

27. Brasil. Decreto n.3.029, de 16 de abril de 1999. Presidente da República aprova o Regulamento da Agência Nacional de Vigilância Sanitária. Diário Oficial da União. 199919 abr; (73):1; Seção1.

28. Brasil. Resolução n.58, de 06 de maio de 1999. A Diretoria Colegiada da ANVISA/M S determina que as publicações da ANVS e SNVS sejam por meio de Resolução. Diário Oficial da União. 19997 maio; (86-E):19; Seção 1.

29. Brasil. Portaria n.710 MS, de 10 de junho de 1999. O M inistério da Saúde aprova a política nacional de alimentação e nutrição. Diário Oficial da União. 199911 jun; (110-E):14; Seção 1.

30. Brasil. Resolução RDC n.15, de 21 de fevereiro de 2000. A Diretoria Colegiada da ANVISA/M S aprova o Regulamento Técnico sobre fortificação de ferro em farinhas de trigo e milho. Diário Oficial da União. 200025 fev; (40-E):24; Seção 1.

31. Brasil. Resolução RDC n.344, de 13 de dezembro de 2002. A Diretoria Colegiada da ANVISA/MS aprova o regulamento técnico para fortificação das farinhas de trigo e das farinhas de milho com ferro e ácido fólico. Diário Oficial da União. 200218 dez; (244):58; Seção 1. 
32. Brasil. Resolução RDC n.94, de 01 de novembro de 2000. A Diretoria Colegiada da ANVISA/MS aprova o regulamento técnico para rotulagem nutricional obrigatória de alimentos e bebidas embalados. Diário Oficial da União. 20003 nov; (212-E):15; Seção 1.

33. Brasil. Resolução RDC n.39, de 21 de março de 2001. A Diretoria Colegiada da ANVISA/M S aprova a tabela de valores de referência para porções de alimentos e bebidas embalados para fins de rotulagem nutricional. Diário Oficial da União. 2001 22 mar; (57-E):17; Seção 1.

34. Philippi ST, Latterza AR, Cruz ATR, Ribeiro LC. Pirâmide alimentar adaptada: guia para a escolha dos alimentos. Rev Nutr. 1999; 1(12):65-80.

35. Brasil. Resolução RDC n.40, de 21 de marco de 2001. A Diretoria Colegiada da ANVISA/M S aprova o regulamento técnico para rotulagem nutricional obrigatória de alimentos e bebidas embalados. Diário Oficial da União. 200122 mar; (57-E): 22; Seção 1.

36. Brasil. Resolução RDC n.259, de 20 de setembro de 2002. A Diretoria Colegiada da ANVISA/MS aprova regulamento técnico sobre rotulagem de alimentos embalados. Diário Oficial da União. 200223 set; (184):33; Seção 1.

37. Brasil. Resolução RDC n.40, de 08 de fevereiro de 2002. A Diretoria Colegiada da ANVISA/M S aprova o regulamento técnico para rotulagem de alimentos e bebidas que contenham glúten. Diário Oficial da União. 200213 fev; (29):34; Seção 1.

38. Brasil. Lei n.10.674, 16 de maio de 2003. O Congresso Nacional obriga que os produtos alimentícios comercializados informem sobre a presença de glúten. Diário Oficial da União. 200319 maio; (94): 1; Seção 1.

39. Brasil. Resolução RDC n.275, de 21 de outubro de 2002. A Diretoria Colegiada da ANVISA/M S aprova regulamento técnico de procedimentos padronizados aplicados aos estabelecimentos produtores/ industrializadores de alimentos e a lista de verificação de boas práticas de fabricação em estabelecimentos produtores/industrializadors de alimentos. Diário Oficial da União. 200223 out; (206): 126; Seção 1.

40. Brasil. Portaria n.218 - M S de 24 de março de 1999. O Ministério da Saúde estabelece a iodação do sal considerado próprio para consumo. Diário Oficial da União. 199925 mar; (57):15; Seção 1.

41. Brasil. Resolução RDC n.32, de 25 de fevereiro de 2003. A Diretoria Colegiada da ANVISA/MS estabelece a iodação do sal considerado próprio para consumo. Diário Oficial da União. 200326 fev; Seção 1.

42. Brasil. Resolução RDC n.130, de 26 de maio de 2003. A Diretoria Colegiada da ANVISA/M S estabelece a iodação do sal considerado próprio para consumo. Diário Oficial da União. 200328 maio; (101):48; Seção 1.

43. Brasil. Resolução RDC n.360, de 23 de dezembro de 2003. A Diretoria Colegiada da ANVISA/MS aprova o regulamento técnico sobre rotulagem nutricional de alimentos embalados. Diário Oficial da União. 200326 dez; (251):33; Seção 1.

44. Brasil. Ministério da Saúde/Agência Nacional de Vigilância Sanitária/Universidade de Brasília. Rotulagem nutricional obrigatória: manual de orientações às indústrias de alimentos. 2a. Versão 44. Brasília; 2005.

45. Brasil. Resolução RDC n.359, de 23 de dezembro de 2003. A Diretoria Colegiada da ANVISA/MS aprova o regulamento técnico de porções de alimentos embalados para fins de rotulagem nutricional. Diário Oficial da União. 200326 dez; (251):28; Seção 1.

Recebido em: 11/7/2005

Versão final reapresentada em:7/8/2006 Aprovado em: 27/11/2006 